\title{
The Exchange Between Proglycogen and Macroglycogen and the Metabolic Role of the Protein-rich Glycogen in Rat Skeletal Muscle
}

\author{
Ming-ta Huang, ${ }^{\star}$ Chin-fang Lee, ${ }^{*}$ Rei-feng Lin, ${ }^{*}$ and Ray-jade Chen ${ }^{\ddagger}$ \\ $*$ Department of Biochemistry and ${ }^{\ddagger}$ Department of Surgery, Chang Gung College of Medicine and Technology, Kwei-san, \\ Tao-yuan, Taiwan
}

\begin{abstract}
The aim of this study is to determine if proglycogen and macroglycogen are kinetically related in rat skeletal muscle. Eight groups of anesthetized fasted rats (seven hepaticoccluded and one nonoccluded) were intravenously infused with $\left[3{ }^{3} \mathrm{H}\right]$ glucose at a rate of $1.7 \mu \mathrm{Ci} \cdot \mathrm{min}^{-1}$ for $20 \mathrm{~min}$. At the end of infusion, hindlimb muscles were excised and rapidly frozen in liquid nitrogen. Proglycogen was extracted by precipitation in 10\% TCA; and macroglycogen as a part of total glycogen by precipitation in $20 \% \mathrm{KOH}-65 \%$ ethanol. Along with the tracer, the occluded rats were also infused with: saline (group 1); insulin at rates ranging from 5 to $50 \mathrm{mU} \cdot \mathrm{min}^{-1}$ (groups 2 to 5); and insulin at a rate of 10 $\mathrm{mU} \cdot \mathrm{min}^{-1}$ plus glucose at rates of 10.2 and $20.4 \mu \mathrm{mol} \cdot \mathrm{min}^{-1}$, respectively (groups 6 and 7). The infusion regimens resulted in up to 30-fold difference in whole-body glucose utilization among the rats. In the rats infused with saline and insulin at a rate of $5 \mathrm{mU} \cdot \mathrm{min}^{-1},\left[{ }^{3} \mathrm{H}\right]$ glucose was found to be exclusively incorporated into proglycogen. Incorporation into macroglycogen was found in the rats infused with insulin at rates $>10 \mathrm{mU} \cdot \mathrm{min}^{-1}$. Supplementary glucose infusion increased the synthesis of $\left[{ }^{3} \mathrm{H}\right]$ proglycogen (four- to sixfold), and equilibrated the two extractable forms of glycogen in the insulin-infused rats. In the saline-infused nonoccluded rats, only proglycogen was found to be labeled. In conclusion, our data indicate that in the intact and hepatic-occluded rats, proglycogen in the skeletal muscles may undergo synthesis and degradation of its own more readily than exchange between itself and depot macroglycogen. (J. Clin. Invest. 1997. 99:501-505.) Key words: proglycogen • macroglycogen $\bullet$ insulin $\bullet$ hepatic inflow occlusion
\end{abstract}

\section{Introduction}

Glycogen is generally thought to be heterogeneous in size with a molecular weight range of $1 \times 10^{6} \sim 1 \times 10^{8} \mathrm{D}(1)$. In 1990 Whelan et al. discovered a new protein-rich form of glycogen in rabbit skeletal muscle, hence the name proglycogen (2). Proglycogen was found to have a molecular weight of $4 \times 10^{5} \mathrm{D}$ and its protein moiety, glycogenin, $3.7 \times 10^{4} \mathrm{D}(2-4)$. Glycoge-

Address correspondence to Dr. Ming-ta Huang, Department of Biochemistry, Chang Gung College of Medicine and Technology, 259 Wen-hua First Road, Kwei-san, Tao-yuan, Taiwan. FAX: 886-3-3283031; E-mail: mthuang@cguaplo.cgu.edu.tw

Received for publication 21 August 1996 and accepted in revised form 22 November 1996.

J. Clin. Invest.

(C) The American Society for Clinical Investigation, Inc. 0021-9738/97/02/0501/05 \$2.00

Volume 99, Number 3, February 1997, 501-505 nin was shown to be an enzyme catalyzing the synthesis of a glycogen primer through a novel glucosyltyrosine linkage between glucose and tyr-194 of its own molecule (3). Proglycogen appears to be similar in physical properties to a bound form of glycogen known as desmoglycogen found by Willstätter and Rhodewald in 1934 (5). The existence of the two pools of glycogen was also suggested 20 years later by Stetten and Stetten who injected rats with $\left[{ }^{14} \mathrm{C}\right]$ glucose, and found that the specific radioactivity (SA) ${ }^{1}$ of bound glycogen to be consistently higher than free glycogen in the liver and skeletal muscle (1).

The discovery of proglycogen and glycogenin has led to new insights into the regulation of glycogen metabolism traditionally known to be regulated at glycogen phosphorylase and glycogen synthase by covalent modification (5). Proglycogen was proposed to be the stable intermediate for the synthesis and breakdown of depot macroglycogen (5). By converting proglycogen into macroglycogen, tissue reserve of glycogen can be expanded (5). The same purpose can be achieved, if glycogenin copies can be increased in the cell through gene expression (5). The overall glycogenesis flux may also be regulated by the self-glucosylating activity of glycogenin through protein phosphorylation-dephosphorylation at a tyrosine residue other than tyr-194 (5).

In view of these new findings, the aim of this study is to investigate how proglycogen and macroglycogen are kinetically linked in rat skeletal muscle, and whether increases in the rate of glycogen synthesis are associated with increases in macroglycogen reserve at the expense of proglycogen. Intact and hepatic-inflow occluded rats (6) were used for this study. The in vivo hepatic-occluded model separates the liver from systemic circulation and allows whole-body glucose utilization to be determined through changes in plasma glucose. It was found that in this model whole-body glucose utilization can be varied by as much as 30-fold, and glycogen synthesis measured by the incorporation of the intravenously infused $\left[3-{ }^{3} \mathrm{H}\right]$ glucose by as much as 55-fold when insulin or insulin plus glucose was infused into the rat. Proglycogen was extracted by precipitation in $10 \%$ TCA (TCA-G), and macroglycogen as a part of total tissue glycogen by precipitation in $20 \% \mathrm{KOH}-65 \%$ ethanol (KOH-G). The kinetic relationship between the two fractions of glycogen (proglycogen and macroglycogen) was determined by comparing the yield and specific radioactivity (SA) of the two extractable forms of labeled glycogen.

\section{Methods}

Materials. Bovine insulin (27.3 USP U/mg) was obtained from Sigma Chemical Company (St. Louis, MO). [3- $\left.{ }^{3} \mathrm{H}\right]$ Glucose $\left(13.5 \mathrm{Ci} \cdot \mathrm{mmol}^{-1}\right.$ ) was obtained from Dupont-New England Nuclear (Wilmington, DE).

1. Abbreviations used in this paper: GIR, glucose infusion rate; SA, specific radioactivity. 
Dowex AG $1 \times 8$ and $50 \mathrm{~W} \times 8$ resins were obtained from BioRad (Richmond, CA). Intramedic PE 10 cannulas were purchased from Clay Adams (Parsippany, NJ). Enzymes for the determination of glycogen and other metabolites were obtained from Boehringer Mannheim (Mannheim, Germany). RIA kit for insulin assay was obtained from CIS Biointernational (France). All other chemicals were obtained from Sigma Chemical Company.

Animal experiments. The following animal protocols were preapproved by an institutional committee on animal experimentation at the Chang Gung Medical College. Male Wistar rats (250-300 g) were maintained individually in metabolic cages, and were allowed free access to food (Purina rat chow) and water until the day before the experiment when food only was removed (fasted for $\sim 20-24 \mathrm{~h}$ ). Rats were divided into eight groups: seven hepatic-occluded and one intact (nonoccluded), each containing five individuals. All rats were anesthetized with ketamine $\left(100 \mathrm{mg} \cdot \mathrm{kg}^{-1}\right.$, i.p. $)$ and were implanted with two cannulas (Intramedic PE 10): one in the aorta for blood sampling, and the other in the inferior vena cava for intravenous infusion before the experiments as previously described (7). In the occluded rats a laparotomy was also made and a piece of 4-O surgical silk was placed loosely around the hepatic triads (portal vein, hepatic artery, and bile duct) (6). The incision in the abdomen was covered with a piece of saline-moistened gauze. The model is similar to the human procedure of Pringle's maneuver (8). After the surgery the animals were placed on a thermal blanket (Harvard Apparatus) for body temperature to be maintained at $37^{\circ} \mathrm{C}$. The initial intraperotoneal dose of ketamine was found to be sufficient to maintain the animals in the anesthetized state throughout the experimental procedure, lasting generally for less than $1 \mathrm{~h}$.

The animals were injected intravenously with heparin $(1,000$ $\left.\mathrm{U} \cdot \mathrm{kg}^{-1}\right)$. 0 -time blood sample $(0.5 \mathrm{ml})$ was taken from the arterial cannula after $10 \mathrm{~min}$. Thereafter, the silk loop around the hepatic triads in the occluded rats was tightened. During the next $20 \mathrm{~min}$, the seven groups of occluded rats were differently infused: group 1 with saline; groups 2-5 with insulin at rates of $5,10,25$, and $100 \mathrm{mU} \cdot \mathrm{min}^{-1}$; groups 6 and 7 with insulin at a rate of $10 \mathrm{mU} \cdot \mathrm{min}^{-1}$ and supplementary glucose at rates of 10.2 and $20.4 \mu \mathrm{mol} \cdot \mathrm{min}^{-1}$. All infusates were administered through the cannula implanted in the inferior vena cava. The one group of intact rats, subjected similarly to ketamineanesthesia and surgical cannulation but without hepatic occlusion, were intravenously infused with saline for $20 \mathrm{~min}$. In all groups of rats, $\left[3-{ }^{3} \mathrm{H}\right]$ glucose was also infused intravenously at a rate of 1.7 $\mu \mathrm{Ci} \cdot \min ^{-1} \cdot\left[3-{ }^{3} \mathrm{H}\right]$ Glucose was purified before use by passing through tandem columns of Dowex AG $1 \times 8(1 \mathrm{ml})$ and Dowex $50 \mathrm{~W} \times 8$ resins $(1 \mathrm{ml})$. The neutral effluents $(10 \mathrm{ml})$ were freeze-dried, dissolved in saline, and stored in a $-30^{\circ} \mathrm{C}$ freezer until use. The concentrations of insulin in the infusion solutions were $65,130,325$, or 649 $\mathrm{mU} \cdot \mathrm{ml}^{-1}$. The solutions were delivered at a fixed rate of 0.077 $\mathrm{ml} \cdot \mathrm{min}^{-1}$. The rates of insulin infusion were estimated to be $5,10,25$, and $50 \mathrm{mU} \cdot \mathrm{min}^{-1}$ in the rats. The infusion solutions for the two groups of rats infused with insulin plus supplementary glucose contained insulin at a concentration of $130 \mathrm{mU} \cdot \mathrm{ml}^{-1}$ and glucose at concentrations of 132 and $265 \mathrm{mM}$.

Blood $(0.5 \mathrm{ml})$ was taken from the aorta at $5,10,15$, and $20 \mathrm{~min}$ during the infusion. Blood loss from the animals was replaced immediately by transfusion using blood obtained from heparinized, fasted, and ketamine-anesthetized donor animals (9). After $20 \mathrm{~min}$, the gastrocnemius mass in the hindlimbs was excised and freeze-clamped immediately in liquid nitrogen. The gastrocnemius group is predominantly a fast-twitch muscle comprising $70 \%$ fast-twitch and $30 \%$ slow-twitch fibers (10). Therefore, results of this study do not discriminate between the two fiber types, rather represent an average of the total muscle. The anesthetized animals were sacrificed by opening the chest through an incision in the diaphragm. Hindlimb muscles were pulverized and stored in a $-80^{\circ} \mathrm{C}$ freezer until analysis.

Glycogen assays. Frozen muscles $(\sim 0.5 \mathrm{~g})$ were weighed and homogenized in $5 \mathrm{ml}$ of $10 \%$ TCA or $2.5 \mathrm{ml}$ of a solution containing $20 \% \mathrm{KOH}$ and $65 \%$ ethanol using a polytron. The TCA extracts were centrifuged $(800 \mathrm{~g}, 20 \mathrm{~min})$ at $4^{\circ} \mathrm{C}$ and the supernatants discarded. The pellets were washed twice with $10 \%$ TCA and once with diethyl ether to remove residual TCA (2). After evaporating the remaining ether, glycogen in the precipitates (TCA-G) was hydrolyzed in $1 \mathrm{~N} \mathrm{HCl}(1 \mathrm{ml})$ at $100^{\circ} \mathrm{C}$ for $1 \mathrm{~h} \mathrm{(11).} \mathrm{The} \mathrm{hydrolysates} \mathrm{were} \mathrm{neu-}$ tralized with $\mathrm{NaOH}$ and centrifuged. The supernatants used for the determination of radioactivity were $0.7 \mathrm{ml}$, and for the determination of glucosyl units $0.02 \mathrm{ml}$, equivalent to extracts of about 0.4 and $0.01 \mathrm{~g}$ of the muscle samples, respectively.

The $\mathrm{KOH}$-ethanol extracts were incubated at $85^{\circ} \mathrm{C}$ for $15 \mathrm{~min}$. After centrifugation $(800 \mathrm{~g}, 20 \mathrm{~min})$, the precipitates were washed twice with $1 \mathrm{ml}$ chloroform:methanol (1:1 vol/vol; 12$)$. The residual organic solvents were evaporated, and glycogen in the precipitates (KOH-G) was hydrolyzed in $1 \mathrm{~N} \mathrm{HCl}$ at $100^{\circ} \mathrm{C}$ for $1 \mathrm{~h}$ (11). The masses of the muscle samples used for the determination of radioactivity and glucosyl units of KOH-G were as described above for TCA-G. Glucosyl units in the glycogen hydrolysates were measured by the hexokinase and glucose-6-phosphate dehydrogenase-linked reduction of $\mathrm{NADP}^{+}(13)$. The solutions for the determination of radioactivity were mixed with $5 \mathrm{ml}$ of scintillation fluid (Aquasol-2; Dupont-New England Nuclear). Radioactivity in counts per minute (cpm) in the hydrolysates was determined in a Beckman 5000 TD counter. The background radioactivity was $\sim 20 \mathrm{cpm}$. The raw data for radioactivity counting in muscle glycogen samples, although low in some instances (e.g., $\sim 250 \mathrm{cpm}$ in saline-infused hepatic-inflow occluded rats), were significantly greater than background radioactivity.

Plasma glucose and insulin. Plasma was deproteinized by $3.6 \%$ perchloric acid (PCA). Glucose in the neutralized PCA extracts was assayed spectrophotometrically by the hexokinase and glucose-6-phosphate dehydrogenase-linked reaction (13). Plasma insulin was determined by radioimmunoassay (14).

Statistics. Data are expressed as means \pm SE. Significance of difference between TCA-G and KOH-G belonging to the same group of animals was tested by paired $t$ test. Significance of difference in groups of animals treated with different doses of insulin or glucose was tested by ANOVA or unpaired $t$ test. Statistical significance was indicated by $P<0.05$.

\section{Results}

Hepatic occlusion. Plasma glucose in fasted intact rats (no hepatic occlusion) infused with saline remained constant at $5.4 \pm 0.4 \mathrm{mM}(n=5)$ over the 20-min experimental period. In contrast, plasma glucose in fasted hepatic-occluded rats infused with saline decreased linearly from $5.8 \pm 0.3 \mathrm{mM}$ to $4.0 \pm 0.3 \mathrm{mM}(n=5)$ after $20 \mathrm{~min}$. From the decline in plasma glucose, whole-body rate of glucose utilization in a $300 \mathrm{~g}$ rat was estimated to be $0.73 \mu \mathrm{mol} \cdot \mathrm{min}^{-1}$, assuming a blood volume of $54 \mathrm{ml} \cdot \mathrm{kg}^{-1}$ and hematocrit of 0.5 (15).

$\mathrm{KOH}-\mathrm{G}$ which contained total tissue glycogen (proglycogen + macroglycogen) in skeletal muscle of the hepatic-occluded rats infused with saline was not significantly different from the intact nonoccluded rats (occluded $29.8 \pm 2.5$ vs. intact $31.0 \pm 2.0$ $\mu$ mol glucosyl units $\cdot \mathrm{g}^{-1}$ wet weight, $n=5$ ). TCA-G which contained the protein-rich proglycogen in the two groups of rats were also found not to be significantly different (occluded $13.9 \pm 1.0$ vs. intact $13.0 \pm 0.2 \mu \mathrm{mol}$ glucosyl units $\cdot \mathrm{g}^{-1}$ wet weight, $n=5$ ). Protein-rich proglycogen as a fraction of total tissue glycogen was found to be about $45 \%$ in these two groups of rats.

The incorporation of $\left[3-{ }^{3} \mathrm{H}\right]$ glucose into TCA-G $(1,048 \pm$ $114 \mathrm{cpm} \cdot \mathrm{g}^{-1}$ wet weight) in the occluded rats was found to be greater than $\mathrm{KOH}-\mathrm{G}\left(620 \pm 85 \mathrm{cpm} \cdot \mathrm{g}^{-1}\right.$ wet weight $)$. However, the difference between the two was not found to be statistically significant $(P=0.069)$. The similarity in yield of radioactivity 
between the two extractable forms of glycogen indicates that all the radioactivity found in total tissue glycogen were from protein-rich proglycogen, macroglycogen was not labeled. The SA of TCA-G $\left(78 \pm 12 \mathrm{cpm} \cdot \mu \mathrm{mol}^{-1}\right.$ glucosyl units) was 3.7 -fold greater than $\mathrm{KOH}-\mathrm{G}\left(21 \pm 3 \mathrm{cpm} \cdot \mu \mathrm{mol}^{-1}\right.$ glucosyl units; $P=0.002$ ).

Insulin infusion in the occluded rats. Insulin was infused at rates ranging from 5 to $50 \mathrm{mU} \cdot \mathrm{min}^{-1}$ to increase whole-body glucose utilization and skeletal muscle glycogen synthesis. Before the infusion, plasma levels of insulin were found to be less than $5 \mu \mathrm{U} \cdot \mathrm{ml}^{-1}$. At the end of infusion, plasma insulin levels were found to be 195 $\pm 190,608 \pm 127,1285 \pm 240$, and $1175 \pm 371 \mu \mathrm{U} \cdot \mathrm{ml}^{-1}$, respectively $(n=5)$, for rates of infusion of $5,10,25$, and $50 \mathrm{mU} \cdot \mathrm{min}^{-1}$. Plasma insulin levels in the latter three groups were found to be similar to or greater than those reported for glucose utilization to be maximally stimulated in awake intact rats $\left(\sim 600 \mathrm{mU} \cdot \mathrm{l}^{-1} ; 15\right)$.

The incorporation of $\left[3-{ }^{3} \mathrm{H}\right]$ glucose into TCA-G and $\mathrm{KOH}-\mathrm{G}$ in hindlimb muscles of the insulin-infused hepatic-occluded rats are shown in Table I. In the rats infused with insulin at a rate of $5 \mathrm{mU} \cdot \mathrm{min}^{-1}$, labeled glucose was found to be incorporated exclusively into proglycogen (TCA-G $2057 \pm 660$ vs. $\left.\mathrm{KOH}-\mathrm{G} 2186 \pm 1451 \mathrm{cpm} \cdot \mathrm{g}^{-1}, \mathrm{n}=5\right)$. The incorporation of $\left[3-{ }^{3} \mathrm{H}\right]$ glucose $\left(\mathrm{cpm} \cdot \mathrm{g}^{-1}\right.$ wet weight) into TCA-G and $\mathrm{KOH}-\mathrm{G}$ increased as the rate of insulin infusion increased (Table I). The yield of radioactivity in KOH-G in the rats infused with insulin at rates $>10 \mathrm{mU} \cdot \mathrm{min}^{-1}$ was found to be significantly greater than TCA-G by $48-58 \%$ (Table I), indicating label incorporation into macroglycogen. The increases in yield of radioactivity in the insulin-infused rats was paralleled with increases in SA in TCA-G or KOH-G (Table I). In all four groups of insulin-infused rats, SA of TCA-G was found to be significantly greater than $\mathrm{KOH}-\mathrm{G}$ (Table I). The degree of difference, however, diminished from $90 \%$ in the rats infused with insulin at the lowest rate $\left(5 \mathrm{mU} \cdot \mathrm{min}^{-1}\right)$ to $20-40 \%$ in rats infused with insulin at the three higher rates (Table I). While the amount of TCA-G in the insulin-infused rats was found to be unchanged, the amount of $\mathrm{KOH}-\mathrm{G}$ was found to decrease by about $20 \%$, as compared to the saline-infused rats (Table I).

Infusion of insulin plus supplementary glucose. Supplementary glucose was also infused into the occluded rats infused with insulin at a rate of $10 \mathrm{mU} \cdot \mathrm{min}^{-1}$. Plasma glucose concentration in the rats infused with insulin alone declined from about $5 \mathrm{mM}$ to $2.1 \pm 0.3 \mathrm{mM}$ at the end of infusion (Fig. 1). The rate of whole-body glucose utilization estimated was 1.50 $\mu \mathrm{mol} \cdot \mathrm{min}^{-1}$, about twofold greater than the saline-infused oc-

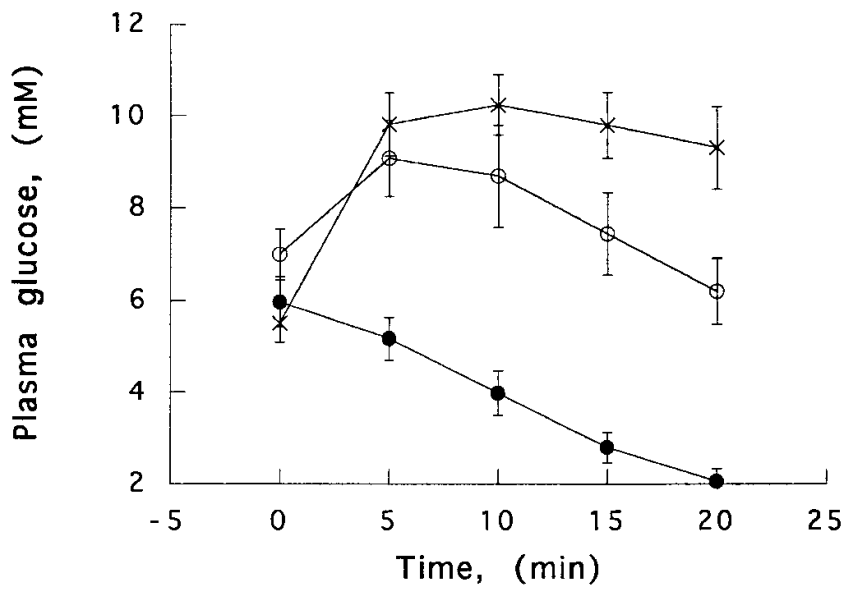

Figure 1. Plasma glucose concentrations in the hepatic-occluded rats infused with insulin at a rate of $10 \mathrm{mU} \cdot \mathrm{min}^{-1}$ plus glucose at a rate of $0(\bullet), 10.2 \mu \mathrm{mol} \cdot \mathrm{min}^{-1}(\bigcirc)$, and $20.4 \mu \mathrm{mol} \cdot \mathrm{min}^{-1}(\times)$. Data are mean $\pm \mathrm{SE}$ of five experiments in each group.

cluded rats. The infusion of supplementary glucose was an attempt to restore plasma glucose to a constant level, a condition allowing whole-body glucose utilization to be measured from the rate of glucose infusion (GIR; 15). A GIR of 10.2 $\mu \mathrm{mol} \cdot \mathrm{min}^{-1}$ could not prevent plasma glucose from falling (Fig. 1). At a GIR of $20.4 \mu \mathrm{mol} \cdot \mathrm{min}^{-1}$, plasma glucose could be maintained at about $9.0 \mathrm{mM}$ for $20 \mathrm{~min}$ in the hepaticoccluded rat (Fig. 1), indicating a whole-body rate of glucose utilization of this magnitude. The rate of glucose utilization in the rats infused with insulin plus supplementary glucose was about 30- and 14-fold greater than the rates estimated from the decline in plasma glucose concentrations for the saline-infused and insulin-infused rats, respectively. The rate of glucose utilization estimated in this study for the hepatic-occluded rats infused with insulin plus supplementary glucose was slightly greater than GIR reported for pentobarbital-anesthetized intact rats $(10 \%)$, but was about $50 \%$ less than GIR determined for awake intact rats by hyperinsulinemic-euglycemic clamp (16).

The incorporation of $\left[3-{ }^{3} \mathrm{H}\right]$ glucose into the two extractable forms of glycogen in the two groups of occluded rats infused with insulin plus supplementary glucose are shown in Table II. The yield of radioactivity ( $\mathrm{cpm} \cdot \mathrm{g}^{-1}$ wet wt) in TCA-G increased 6.2-fold and $\mathrm{KOH}-\mathrm{G}$ 6.7-fold in the rats infused with

Table I. TCA-precipitable (TCA-G) and KOH-precipitable Glycogen (KOH-G) in Hindlimb Muscles of Fasted Anesthetized Rats Intravenously Infused with Insulin at Rates of $(A) 5,(B) 10,(C) 25$, and (D) $50 \mathrm{mU} \cdot \mathrm{min}^{-1}$ during a 20-min Period of Hepatic Inflow Occlusion

\begin{tabular}{|c|c|c|c|c|c|c|c|c|}
\hline & \multicolumn{2}{|c|}{ A } & \multicolumn{2}{|c|}{ B } & \multicolumn{2}{|c|}{$\mathrm{C}$} & \multicolumn{2}{|c|}{ D } \\
\hline & TCA-G & KOH-G & TCA-G & KOH-G & TCA-G & KOH-G & TCA-G & KOH-G \\
\hline $\begin{array}{l}{\left[{ }^{3} \mathrm{H}\right] \text { glycogen }} \\
\quad\left(\mathrm{cpm} \cdot \mathrm{g}^{-1} \times 10^{-4}\right)\end{array}$ & $0.21 \pm 0.07$ & $0.22 \pm 0.15$ & $0.33 \pm 0.03$ & $0.52 \pm 0.05^{*}$ & $0.63 \pm 0.07^{\ddagger \S}$ & $0.93 \pm 0.08 * \ddagger \S$ & $0.51 \pm 0.08^{\ddagger \S}$ & $0.81 \pm 0.10^{* \neq \$}$ \\
\hline Amount $\left(\mu \mathrm{mol} \cdot \mathrm{g}^{-1}\right)$ & $13.2 \pm 1.0$ & $24.9 \pm 2.1^{*}$ & $13.5 \pm 1.4$ & $25.2 \pm 1.0^{*}$ & $14.1 \pm 0.6$ & $26.3 \pm 0.3 *$ & $12.3 \pm 0.6$ & $25.9 \pm 2.8^{*}$ \\
\hline $\mathrm{SA}\left(\mathrm{cpm} \cdot \mu \mathrm{mol}^{-1}\right)$ & $148 \pm 35$ & $79 \pm 47 *$ & $247 \pm 23$ & $206 \pm 21 *$ & $452 \pm 46^{\ddagger \S}$ & $354 \pm 31 * \neq \$$ & $474 \pm 66^{\ddagger \S}$ & $336 \pm 70 * \neq \$$ \\
\hline
\end{tabular}

Data are means \pm SE of five experiments. ${ }^{*} P<0.05 \mathrm{vs}$. TCA-G of the same treatment group, paired $t$ test. ${ }^{\ddagger} P<0.05$ vs. group A, ${ }^{\S} P<0.05$ vs. group B, ANOVA. 
Table II. TCA-precipitable (TCA-G) and KOH-precipitable (KOH-G) in Hindlimb Muscles in Fasted Anesthetized Rats Intravenously Infused with Insulin at a Rate of $10 \mathrm{mU} \cdot \mathrm{min}^{-1}$ Plus Supplementary Glucose at a Rate of $(A) 10.2 \mu \mathrm{mol} \cdot \mathrm{min}^{-1}$ and (B) $20.4 \mu \mathrm{mol} \cdot \mathrm{min}^{-1}$ during a 20-min Period of Hepatic Occlusion

\begin{tabular}{|c|c|c|c|c|}
\hline & \multicolumn{2}{|c|}{ A } & \multicolumn{2}{|c|}{ B } \\
\hline & TCA-G & KOH-G & TCA-G & KOH-G \\
\hline $\begin{array}{l}{\left[{ }^{3} \mathrm{H}\right] \text { glycogen }} \\
\quad\left(\mathrm{cpm} \cdot \mathrm{g}^{-1} \times 10^{-4}\right)\end{array}$ & $1.39 \pm 0.03$ & $2.78 \pm 0.05^{*}$ & $2.02 \pm 0.33$ & $3.44 \pm 0.61$ \\
\hline Amount $\left(\mu \mathrm{mol} \cdot \mathrm{g}^{-1}\right)$ & $14.0 \pm 0.9$ & $33.7 \pm 1.6^{*}$ & $16.4 \pm 1.5$ & $29.6 \pm 2.7 *$ \\
\hline $\mathrm{SA}\left(\mathrm{cpm} \cdot \mu \mathrm{mol}^{-1}\right)$ & $979 \pm 157$ & $825 \pm 140$ & $1,200 \pm 116$ & $1,139 \pm 150$ \\
\hline
\end{tabular}

Data are means $\pm \mathrm{SE}$ of five experiments in each group. $* P<0.05$ vs. TCA-G of the same treatment group, paired $t$ test.

supplementary glucose $\left(20.4 \mu \mathrm{mol} \cdot \mathrm{min}^{-1}\right)$ as compared to the rats infused with insulin alone (Tables I and II). The yield of radioactivity in $\mathrm{KOH}-\mathrm{G}$ was found to be significantly greater than TCA-G $(70 \%)$, indicating labeling of not only proteinrich proglycogen but also macroglycogen in the skeletal muscle.

While the amounts of TCA-G in the rats infused with insulin alone and with supplementary glucose $\left(10 \mu \mathrm{mol} \cdot \mathrm{min}^{-1}\right)$ were not found to be different, the amount of $\mathrm{KOH}-\mathrm{G}$ ( $\mu \mathrm{mol} \cdot \mathrm{g}^{-1}$ wet weight) in the rats infused with the low dose of supplementary glucose was found to be greater by about $20 \%$ than the rats infused with insulin alone (Tables I and II). $\mathrm{KOH}-\mathrm{G}$ increased but not significantly in the rats infused with the high-dose of supplementary glucose $\left(20.4 \mu \mathrm{mol} \cdot \mathrm{min}^{-1}\right)$. The SA in both TCA-G and KOH-G in rats infused with supplementary glucose increased fivefold and 5.5-fold, respectively, as compared to the rats infused with insulin alone (Tables I and II). Unlike other groups of hepatic-occluded rats, SA of the two extractable forms of glycogen in the rats infused with supplementary glucose were found to become equilibrated (Table II).

Label incorporation into TCA-G and $\mathrm{KOH}-\mathrm{G}$ in intact rats. The incorporation of $\left[3-{ }^{3} \mathrm{H}\right]$ glucose into TCA-G and $\mathrm{KOH}-\mathrm{G}$ in ketamine-anesthetized intact rats were also studied. Intact rats were infused with saline and $\left[3-{ }^{3} \mathrm{H}\right]$ glucose at a rate similar to that for the occluded rats. The radioactivity incorporated into TCA-G and KOH-G were found to be identical (TCA-G $1,970 \pm 113$ vs. KOH-G $2040 \pm 272 \mathrm{cpm} \cdot \mathrm{g}^{-1}$ wet weight, $n=5)$, indicating incorporation of $[3-3 \mathrm{H}]$ glucose exclusively into TCA-extractable glycogen. The SA of TCA-G $\left(119 \pm 8 \mathrm{cpm} \cdot \mu \mathrm{mol}^{-1}\right)$ was about $80 \%$ greater than $\mathrm{KOH}-\mathrm{G}$ $\left(65 \pm 8 \mathrm{cpm} \cdot \mu \mathrm{mol}^{-1} ; P<0.001, n=5\right.$, unpaired $t$ test), reflecting again the $1: 2$ ratio in glucosyl units between TCA-G and $\mathrm{KOH}-\mathrm{G}$ as was in the hepatic-occluded rats.

\section{Discussion}

Differential incorporation of $\left[{ }^{3} H\right]$ glucose. In this report, the metabolic role of proglycogen in rat skeletal muscle was studied. Proglycogen was extracted as protein-rich glycogen by precipitation in $10 \%$ TCA (TCA-G) (2), while total tissue glycogen containing both proglycogen and macroglycogen was extracted by precipitation in $\mathrm{KOH}$-ethanol (KOH-G; 12). The two extractable forms of glycogen were labeled by $\left[3-{ }^{3} \mathrm{H}\right]$ glu- cose infused intravenously for $20 \mathrm{~min}$. The infused $[3-3 \mathrm{H}]$ glucose was found to be exclusively incorporated into TCA-G in three groups of rats: $(a)$ anesthetized intact rats infused with saline, $(b)$ hepatic-occluded rats infused with saline, and (c) hepatic-occluded rats infused with insulin at a rate of 5 $\mathrm{mU} \cdot \mathrm{min}^{-1}$. Macroglycogen in skeletal muscle in these three groups of rats was not labeled, because the yields of radioactivity ( $\mathrm{cpm} \cdot \mathrm{g}^{-1}$ tissue wet weight) in TCA-G and $\mathrm{KOH}-\mathrm{G}$ were found to be identical.

The incorporation of $\left[3-{ }^{3} \mathrm{H}\right]$ glucose into macroglycogen, as indicated by excess recovery of $\left[{ }^{3} \mathrm{H}\right] \mathrm{glycogen}\left(\mathrm{cpm} \cdot \mathrm{g}^{-1}\right.$ wet weight) in KOH-G than TCA-G, became apparent in the hepatic-occluded rats infused with insulin or insulin plus supplementary glucose. Intravenous infusion of insulin at rates $>10$ $\mathrm{mU} \cdot \mathrm{min}^{-1}$ in the hepatic-occluded rats resulted in moderate increases in the recovery of radioactivity in $\left[{ }^{3} \mathrm{H}\right]$ glycogen, while the infusion of insulin plus supplementary glucose resulted in maximal increase in the recovery of radioactivity in $\left[{ }^{3} \mathrm{H}\right]$ glycogen in the present study. The SA, estimated by dividing isotope yield of glycogen by tissue content of glycogen, was found to be significantly greater in TCA-G than KOH-G under moderate stimulation (Table I). Isotopic equilibrium between different fractions of tissue glycogen was found in the rats infused with insulin plus supplementary glucose (Table II).

Metabolic roles of proglycogen and macroglycogen. Proglycogen has been proposed to be an intermediate for the synthesis and breakdown of depot macroglycogen (5). The incorporation of $\left[{ }^{3} \mathrm{H}\right]$ glucose exclusively into TCA-G in fasted intact rats anesthetized with ketamine and hepatic-occluded rats infused with saline or low rate of insulin indicates that proglycogen is the only fraction of tissue glycogen undergoing turnover. That macroglycogen is metabolically inactive indicates that there is no exchange between proglycogen and macroglycogen under these conditions. Macroglycogen was recruited in muscle glycogen turnover under conditions of moderate increases in $\left[{ }^{3} \mathrm{H}\right]$ glycogen synthesis as in the insulin-infused rats. Further increases in $\left[{ }^{3} \mathrm{H}\right]$ glycogen synthesis resulted in isotopic equilibrium between proglycogen and macroglycogen, indicating exchange between the two forms of glycogen in the skeletal muscle.

It has also been proposed that by converting proglycogen to macroglycogen glycogen reserve in the muscle may be greatly expanded as in glycogen supercompensation (5). In the present study, muscle reserve of glycogen was found to change in two occasions: $(a)$ a decrease of $20 \%$ in $\mathrm{KOH}-\mathrm{G}$ in the insulin-infused rats compared to the saline-infused rats (Table I); and $(b)$ increases of $20 \%$ in $\mathrm{KOH}-\mathrm{G}$ in the rats infused with insulin plus supplementary glucose compared to the rats infused with insulin alone (Tables I and II). In both situations, glycogen contents in TCA-G were either found to be the same (insulin-infused rats and rats infused with supplementary glucose at a rate of $10.2 \mu \mathrm{mol} \cdot \mathrm{min}^{-1}$ ), or increased (supplementary glucose at a rate of $20.4 \mu \mathrm{mol} \cdot \mathrm{min}^{-1}$ ). The former suggests that macroglycogen only, not proglycogen is associated with the increase in the turnover of macroglycogen, and the latter proglycogen is the site for the increase in glycogen deposition. These data collectively indicate that increases in the turnover of macroglycogen do not result in significant changes in glucosyl units in proglycogen. The increases in macroglycogen turnover may involve addition or subtraction of glucosyl units to and from glycogen molecules in the weight range of $10^{6}-10^{8} \mathrm{D}$.

The hepatic-occluded model. The hepatic-occluded rat model 
was selected, because we have found in this model that wholebody glucose utilization and glycogen synthesis can be varied greatly. Whole-body glucose utilization in the rats can be measured from the decline in plasma glucose, because endogenous source of glucose from the liver is blocked. In trying to find a GIR to maintain plasma glucose concentration at a constant level, a strategy similar to the widely-used technique of euglycemic clamp $(15,17,18)$, we found that the selected rate of infusion had to be substantially greater (14-fold) than the rate of glucose utilization estimated from the decline in plasma glucose in rats infused with insulin alone (Fig. 1). The difference in rates of glucose utilization between the two groups of rats may be overestimated and may be reduced to 2.5 -fold, if glucose distribution space instead of plasma volume was used in rate calculation for the insulin-infused rats (19). A separate effect for glucose to stimulate whole-body glucose utilization in the presence of hyperinsulinemia has been reported previously by others $(17,18,20,21)$.

The hepatic-occluded model allowed the synthesis of $\left[{ }^{3} \mathrm{H}\right] \mathrm{gly}-$ cogen to be varied by more than 55-fold when treated with the different infusion regimens. Because the SA of the precursor pool (UDP-glucose) is not known, true rates of glycogen synthesis can not be calculated. The SA of plasma $\left[3-{ }^{3} \mathrm{H}\right]$ glucose has been suggested to be used as a substitute for UDP-glucose (22). However, since our primary objective is to determine the difference in labeling between the two forms of glycogen within a wide-range of difference in glycogen synthesis in the muscle, we did not pursue further rate calculation for glycogen synthesis in this report.

Conclusion. In summary, our data indicate that proglycogen is the only fraction of muscle glycogen undergoing synthesis and degradation when the rate of glycogen turnover is low, as are in the ketamine-anesthetized intact (nonoccluded) rats and hepatic-occluded rats infused with saline or a low dose of insulin $\left(5 \mathrm{mU} \cdot \mathrm{min}^{-1}\right)$. When the rate of glycogen synthesis increases, however, macroglycogen is also recruited in glycogen turnover. Initially, the precursors and products of macroglycogen turnover involve only glycogen in the molecular weight range of $10^{6}-10^{8} \mathrm{D}$. Upon further increases in macroglycogen turnover, glycogen molecules belonging to a lower weight range are involved (proglycogen included), leading eventually to equilibration in specific activities between proglycogen and macroglycogen. Because glucosyl units in TCA-G $(\sim 14$ $\mu \mathrm{mol} \cdot \mathrm{g}^{-1}$ wet weight) and the ratio between TCA-G and $\mathrm{KOH}-\mathrm{G}(40-50 \%)$ were found to vary within narrow ranges under the present conditions, it is suggested that transition from an inactive to an active state of proglycogen-macroglycogen exchange in rat skeletal muscles is not associated with a net conversion of proglycogen to macroglycogen.

\section{Acknowledgements}

This study was supported by the Chang Gung Medical Center (CMRP 347) and by the National Science Council of the ROC gov- ernment in Taiwan (NSC85-2331-B182-029, NSC86-2314-B182-011, and NSC85-2331-B182A-017).

\section{References}

1. Stetten, D., and M.R. Stetten. 1960. Glycogen metabolism. Physiol. Rev. 402:505-537.

2. Lomako, J.L., W.M. Lomako, and W.J. Whelan. 1990. Proglycogen: a low-molecular-weight form of muscle glycogen. FEBS Lett. 279:223-228.

3. Rodriguez, I.R., and W.J. Whelan. 1985. A novel glucosyl-amino acid linkage: rabbit-muscle glycogen is covalently linked to a protein via tyrosine. Biochem. Biophys. Res. Commun. 132:829-836.

4. Smythe, C., F.B. Caudwell, M. Ferguson and P. Cohen. 1988. Isolation and structural analysis of a peptide containing the novel tyrosyl-glucose linkage in glycogenin. EMBO (Eur. Mol. Biol. Organ) J. 7:2681-2686.

5. Alonso, M.D., J. Lomako, W.M. Lomako, and W.J. Whelan. 1995. A new look at the biosynthesis of glycogen. FASEB J. 9:1126-1137.

6. Kogure, K., and M. Suzuki. 1992. Effects of hepatic inflow occlusion on changes in plasma potassium, histamine and norepinephrine in rats. Circ. Shock 36:290-298.

7. Huang, M.-T. 1991. Simple validation for the hepatic venous cannula implanted chronically in conscious rats. J. Appl. Physiol. 71:359-364.

8. Feliciano, D.V., K.L. Mattox, G.L. Jordan, J.M. Burch, C.G. Bitondo, and P.A. Cruse. 1986. Management of 1000 consecutive cases of hepatic trauma (1979-1984). Ann. Surg. 204:438-445.

9. Huang, M.-T., J.-F. Lin, and C.-F. Lee. 1996. The effect of xenobiotic acetylation on interorgan metabolism of glucose in fasted rats. Life Sci. 58:935944.

10. Aragon, J.J., R.B. Armstrong, and V.R. Edgerton. 1973. Hindlimb muscle fiber populations of five mammals. J. Histochem. Cytochem. 21:51-55.

11. Fürnsinn, C., H. Leuvenink, M. Roden, P. Nowotny, B. Schneider, M. Rohac, T. Pieber, M. Clodi, and W. Waldhäusl. 1994. Ilet amyloid polypeptide inhibits insulin secretion in conscious rats. Am. J. Physiol. 267:E300-E305.

12. Huang, M.-T., and R. L. Veech. 1988. Roles of the direct and indirect pathways for glycogen synthesis in rat liver in the postprandial state. J. Clin. Invest. 81:872-878.

13. Bergmeyer, H.U., E. Bernt, F. Schmidt, and H. Stork. 1974. D-Glucose. Determination with hexokinase and glucose-6-phosphate dehydrogenase. In Methods for enzymatic analysis. H.U. Bergmeyer, editor. Academic Press, New York. 1196-1201.

14. Yalow, R.S., and S.A. Berson. 1960. Immunoassay of endogenous plasma insulin in man. J. Clin. Invest. 39:1157-1175.

15. Kraegen, E.W., D.E. James, S.P. Bennet, and D.J. Chisholme. 1983. In vivo insulin sensitivity in the rat determined by euglycemic clamp. Am. J. Physiol. 245:E1-E7.

16. Clark, P.W., A.B. Jenkins, and E.W. Kraegen. 1990. Pentobarbital reduces basal liver glucose output and its insulin suppression in rats. Am. J. Physiol. 258:E701-E707.

17. Christopher, M.J., C. Rantzau, G.M. Ward, and F.P. Alford. 1995. Insulinopenia and hyperglycemia influence the in vivo partitioning of GE and SI Am. J. Physiol. 268:E410-E421.

18. Del Prato, S., A. Riccio, S.V. De Kreutzenberg, M. Dorella, A. Tiengo, and R.A. DeFronzo. 1995. Basal plasma insulin levels exert a qualitative but not quantitative effect on glucose-mediated glucose uptake. Am. J. Physiol. 268:E1089-E1095.

19. Finegood, D.T., R.N. Bergman, and M. Vranic. 1987. Estimation of endogenous glucose production during hyperinsulinemic-euglycemic glucose clamps. Comparison of unlabeled and labeled exogenous glucose infusates. $\mathrm{Di}$ abetes. 33:914-924.

20. Gottesman, I., L. Mandarino, C. Verdonk, R. Rizza, and J. Gerich. 1982 Insulin increases the maximum velocity for glucose uptake without altering the Michaelis constant in man. Evidence that insulin increases glucose uptake merely by providing additional transport sites. J. Clin. Invest. 70:1310-1314.

21. Yki-Jarvinen, H., A.A. Young, C. Lamkin, and J.E. Foley. 1987. Kinetics of glucose disposal in whole body and across the forearm in man. J. Clin. Invest. 79:1713-1719.

22. Laughlin, M.R., C. Morgan, and E.J. Barrett. 1991. Hypoxemic stimulation of heart glycogen synthase and synthesis. Effects of insulin and diabetes mellitus. Diabetes 40:385-390. 